\title{
Optoelectronic Characteristics of UV Photodetector Based on ZnO Nanopillar Thin Films Prepared by Sol-Gel Method
}

\author{
K. J. Chen ${ }^{1}$, F. Y. Hung ${ }^{2, *}$, S. J. Chang ${ }^{1}$ and S. J. Young ${ }^{1}$ \\ ${ }^{1}$ Institute of Microelectronics \& Department of Electrical Engineering, Center for Micro/Nano Science and Technology, \\ National Cheng Kung University, Tainan 701, Taiwan, R.O.China \\ ${ }^{2}$ Institute of Nanotechnology and Microsystems Engineering, Center for Micro/Nano Science and Technology, \\ National Cheng Kung University, Tainan 701, Taiwan, R.O.China
}

$\mathrm{ZnO}$ thin films were prepared on a quartz substrate by sol-gel method and a UV photodetector was constructed on the $\mathrm{ZnO}$ thin films, with a circular spiral structure in contact with $30 \mathrm{~nm} \mathrm{IrO}_{2}$ electrodes. The $\mathrm{ZnO}$ thin films were crystallized at various crystallized temperature $\left(600 \sim 700^{\circ} \mathrm{C}\right)$ for 1 hour in pure oxygen atmosphere, and were then analyzed by X-ray diffraction (XRD) and the scanning electron microscopy (SEM) to investigate the thin film crystallized structures. From photoluminescence (PL) and I-V measurement, the $650^{\circ} \mathrm{C}$ thin film not only possessed a better crystallization but also had nanopillar structures that revealed an excellent characteristic of UV photodetector. [doi:10.2320/matertrans.MER2008371]

(Received October 10, 2008; Accepted February 9, 2009; Published March 25, 2009)

Keywords: $\mathrm{ZnO}$, thin film, nanopillar, iridium

\section{Introduction}

Photodetectors operating in the UV region are important devices that can be used in many commercial and military applications, such as ozone layer monitoring, flame detection and missile warning systems ${ }^{1,2)}$ etc. In recent years, UV photodetectors have been fabricated on wide direct bandgap materials. Notably, $\mathrm{ZnO}$ possesses a wide direct band-gap energy of $3.37 \mathrm{eV}$ and a larger exciton-binding energy of $60 \mathrm{meV},{ }^{3)}$ that have been used by several deposition techniques, such as RF magnetron sputtering, molecular beam epitaxy (MBE), metal organic chemical vapor deposition (MOCVD), pulsed laser deposition (PLD) and the solgel process. ${ }^{4-8)}$ Among these methods, the sol-gel method enjoys the advantages of being able to prepare large area $\mathrm{ZnO}$ thin films at low cost and easy technology. ${ }^{9}$ ) Therefore, several investigations have prepared UV photodetectors using sol-gel synthesized $\mathrm{ZnO}$ thin films. ${ }^{10,11)}$ However, how the crystallization of sol-gel $\mathrm{ZnO}$ thin film affects the optoelectronic characteristics has still not been investigated. In addition, almost all the photodetector devices used interdigital (IDT) circular structures as contact electrodes, ${ }^{12,13)}$ and the effect of the spiral configuration is worthy of further investigation.

To improve the quality of the photodetector, the metal electrodes need a higher work function and a higher thermal stability. ${ }^{14,15)}$ But, many electrodes with high work function are not stable at higher temperatures. Iridium (Ir) metal has some advantages in terms of thermal $\left(1000^{\circ} \mathrm{C}\right)$ and chemical stability. ${ }^{16,17)}$ In addition, iridium oxide $\left(\mathrm{IrO}_{2}\right)$ also has some advantages, such as high work function $(>5 \mathrm{eV})$, excellent thermal stability and high transmittance, ${ }^{18,19)}$ and so can be used in the electrodes of photodetectors. ${ }^{20,21)}$

For these reasons, this study used sol-gel derived $\mathrm{ZnO}$ thin films with an $30 \mathrm{~nm} \mathrm{IrO}_{2}$ electrode to fabricate the UV photodetector, on order not only to understand the effect of

*Corresponding author, E-mail: fyhung@mail.mse.ncku.edu.tw different crystallizations, but also investigate the contribution of the spiral electrode configuration.

\section{Experimental Procedure}

The $\mathrm{ZnO}$ thin films were deposited on the quartz substrate using the sol-gel method. To prepare the aqueous solution of $\mathrm{ZnO}, 2 \mathrm{M}$ zinc acetate dihydrate $\left(\mathrm{Zn}\left(\mathrm{CH}_{3} \mathrm{COO}\right)_{2} \cdot 2 \mathrm{H}_{2} \mathrm{O}\right)$ was synthesized with a diethanolamine (DEA) in hydranal methanol (dry $\leq 0.01 \%$ water), and the molar ratio of DEA to zinc acetate was $1 .^{22)}$ The aqueous solution was stirred at $140^{\circ} \mathrm{C}$ for $3 \mathrm{~h}$ to form a homogeneous and transparent solution. The spin coating method with a rotation rate of $3000 \mathrm{rpm}$ was used to coat all substrates. After that, the film samples were dried at $200^{\circ} \mathrm{C}$ for $10 \mathrm{~min}$ to evaporate the solvent and remove organic residuals, and then were naturally cooled to room temperature (10 times condecutively). Finally, the film samples were subjected to different crystallizing temperatures $\left(600,650\right.$ and $\left.700^{\circ} \mathrm{C}\right)$ for $1 \mathrm{~h}$ under $\mathrm{O}_{2}$ atmosphere with a flow rate of $50 \mathrm{sccm}$. The thickness of the $\mathrm{ZnO}$ thin film was approximately $250 \mathrm{~nm}$ which was measured by a dual-beam focused ion beam (FIB) (not given here).

The response area (contact area) of UV photodetector with the circular spiral electrode configuration was bigger than that of the interdigital electrode configuration. ${ }^{12,13)}$ Therefore, UV photodetectors were fabricated and based on circular spiral metal-semiconductor-metal (MSM) structures. Iridium (Ir) film of thickness $30 \mathrm{~nm}$ was patterned onto the surface of sol-gel derived $\mathrm{ZnO}$ film by electron beam evaporation to serve as the metal contacts. The width and space of the contact electrodes were $300 \mu \mathrm{m}$, and the active area of the UV photodetector was $6000 \times 4000 \mu \mathrm{m}^{2}$. Notably, the optical transmittance of $\mathrm{IrO}_{2}$ was higher than that of Ir. ${ }^{18,19)}$ In order to improve the quality of electrode, the Ir electrode contact was annealed at $500^{\circ} \mathrm{C}$ for 10 min under an $\mathrm{O}_{2}$ atmosphere with a flow rate of $50 \mathrm{sccm}$ to form $\mathrm{IrO}_{2}$. The schematic structure of the MSM UV photodetectors is shown in Fig. 1. 


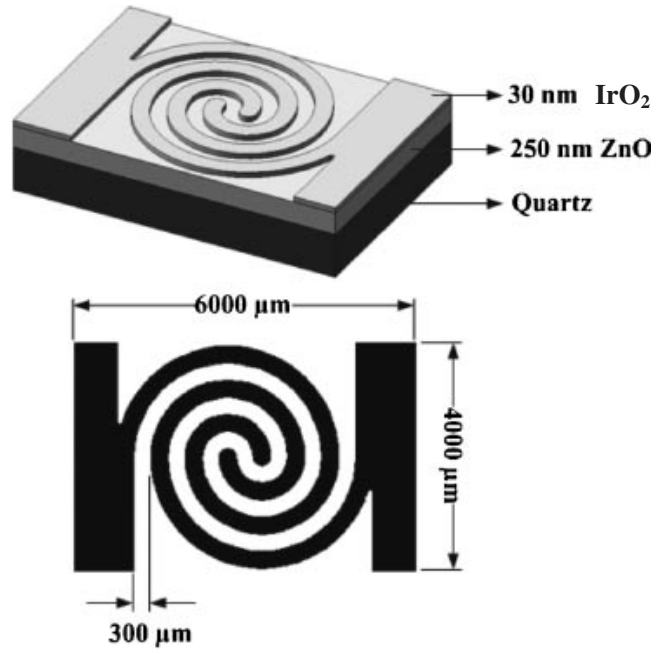

Fig. 1 The schematic structure of ZnO MSM photodetector.

In addition, the crystalline structure was analyzed by thinfilm X-ray diffraction (XRD) with $\mathrm{CuK}_{\alpha}$ radiation. The surface morphology of $\mathrm{ZnO}$ samples was obtained with a working distance of $5 \mathrm{~mm}$, a beam current of $98 \mathrm{pA}$ and a high speed voltage of $5.0 \mathrm{kV}$ via attached the scanning electron microscopy (SEM) of a dual-beam focused ion beam (DB-FIB: Nova NanoLab 200). The photoluminescence (PL) measurement was used to analyze the optical properties of $\mathrm{ZnO}$ crystallization by $325 \mathrm{~nm}$ UV light from a He-Cd laser at room temperature. Also, the current-voltage (I-V) characteristics of the devices were measured by a HP 4145 under the dark and illumination. The top-illuminated spectral response was quantified using a $250 \mathrm{~W}$ xenon (Xe) arc lamp white light source through the monochrometer (The spot size of monochromatic light was about $3000 \mu \mathrm{m}$ ) and calibrated for a monochromatic detection in the range of $300 \sim 450 \mathrm{~nm}$.

\section{Results and Discussion}

\subsection{Structural characteristics}

The XRD patterns of $\mathrm{ZnO}$ thin films with different crystallization temperatures $\left(600,650\right.$ and $\left.700^{\circ} \mathrm{C}\right)$ are shown in Fig. 2. All the $\mathrm{ZnO}$ thin films corresponded to the wurzitetype $\mathrm{ZnO}$ structure and preferred an orientation of (002). With increasing the crystallization temperature from 600 to $650^{\circ} \mathrm{C}$, the intensity of the (002) diffraction peak increased, revealing that the crystallization of the $\mathrm{ZnO}$ thin film was improved by an adequate supply of thermal energy. ${ }^{22}$ In general, the quality of the $\mathrm{ZnO}$ films was able to be improved by increasing the annealing temperature. ${ }^{23-25)}$ However, the crystallization mechanism of the $\mathrm{ZnO}$ thin film began to deteriorate at $700^{\circ} \mathrm{C}$. The main reason is that variations in the grain boundary energy made some of the grains grow unusually and destroyed the crystallization of the $\mathrm{ZnO}$ thin film under higher crystallization temperatures.

For $650^{\circ} \mathrm{C} \mathrm{ZnO}$ film, the (002) diffraction peak at $2 \theta=34.7^{\circ}$ with a FWHM of $0.38^{\circ}$ showed the excellent quality of the $\mathrm{ZnO}$ thin film. The surface morphology of the $650^{\circ} \mathrm{C} \mathrm{ZnO}$ thin film is shown in Fig. 3. The film shows a large amount of grain boundaries and a few micro-pore structures scattered on the surface. These micro-pore struc-

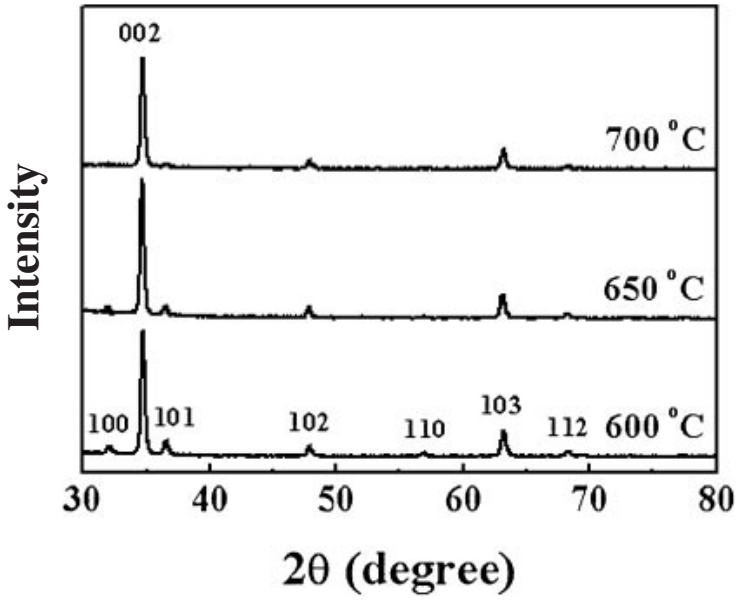

Fig. 2 XRD patterns of $\mathrm{ZnO}$ thin films with different crystallized temperature.

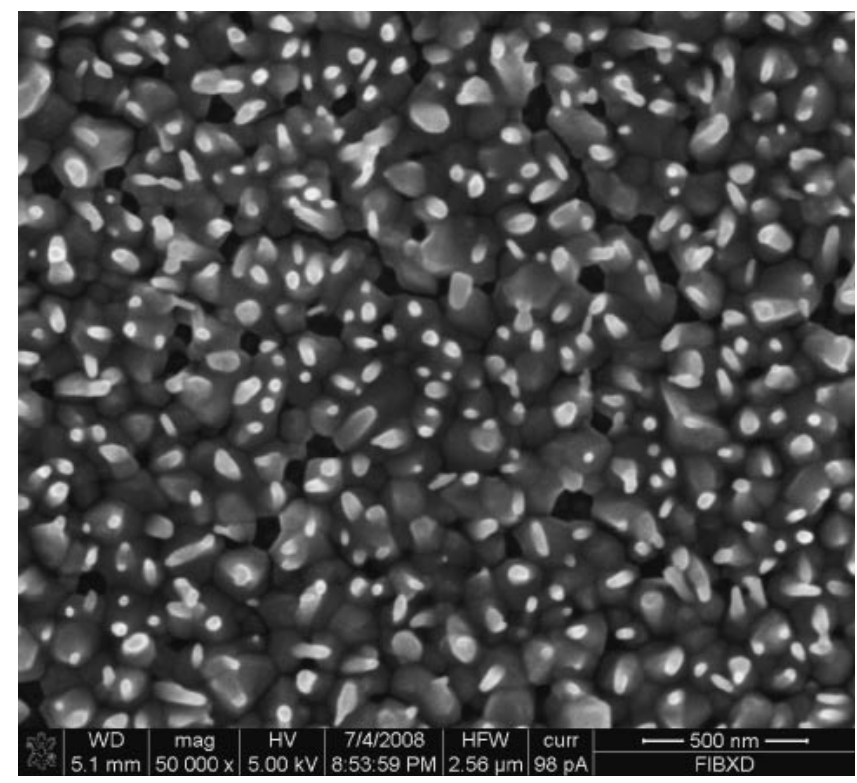

Fig. 3 The surface morphology of $650^{\circ} \mathrm{C} \mathrm{ZnO}$ film.

tures are certain to appear on the sol-gel synthesized $\mathrm{ZnO}$ thin films. ${ }^{25)}$ Notably, some nucleus-like structure was found on the grain surface (Fig. 3). When the surface image was rotated from $0^{\circ}$ to $52^{\circ}$ using FIB (from top view to side view), the nucleus-like structure could be identified as $\mathrm{ZnO}$ nanopillars (Fig. 4). The length of the nanopillars was approximately $\sim 90 \mathrm{~nm}$ and grew disorderly on the film matrix. This result was that the residual zinc reacted with oxygen to form the $\mathrm{ZnO}$ nuclei. Increasing the duration of crystallization, the $\mathrm{ZnO}$ nuclei individually grew to form the $\mathrm{ZnO}$ nanopillars. However, under higher crystallization temperatures, the unusual growth of the grains not only restrained the growth of the $\mathrm{ZnO}$ nanowires, but also destroyed the crystallization. This is why the $650^{\circ} \mathrm{C} \mathrm{ZnO}$ thin film possessed the best crystallization mechanism.

\subsection{Optical and electrical properties}

The $650^{\circ} \mathrm{C}$ films had excellent crystallized structures with nanopillars. Photoluminescence (PL) was used to check its optical quality. Figure 5 shows the PL spectrum (room 


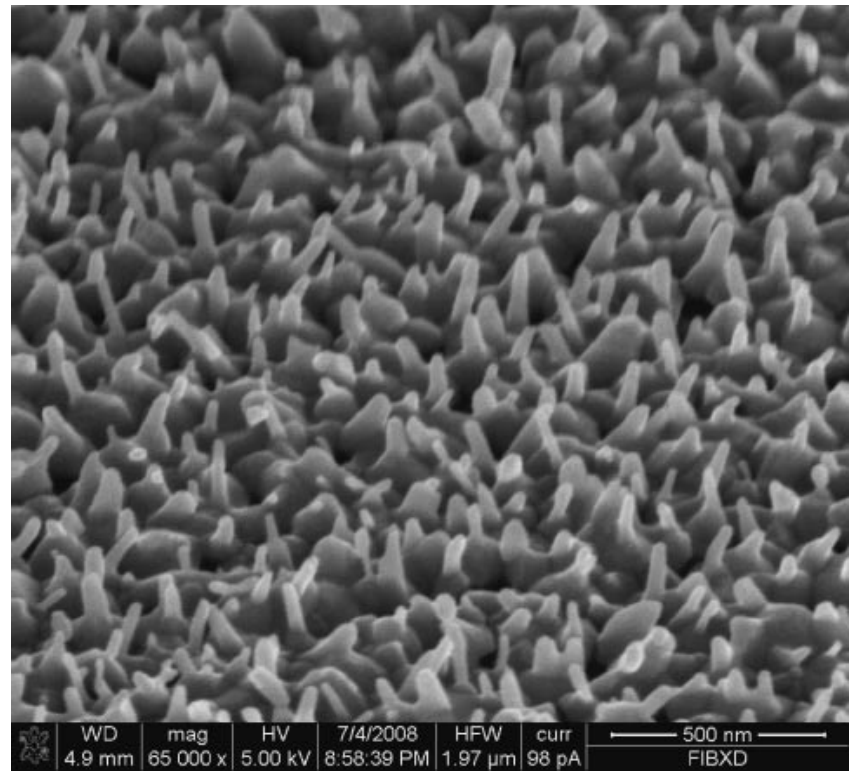

Fig. 4 Surface characteristic of $650^{\circ} \mathrm{C} \mathrm{ZnO}$ film with nanowires (using FIB).

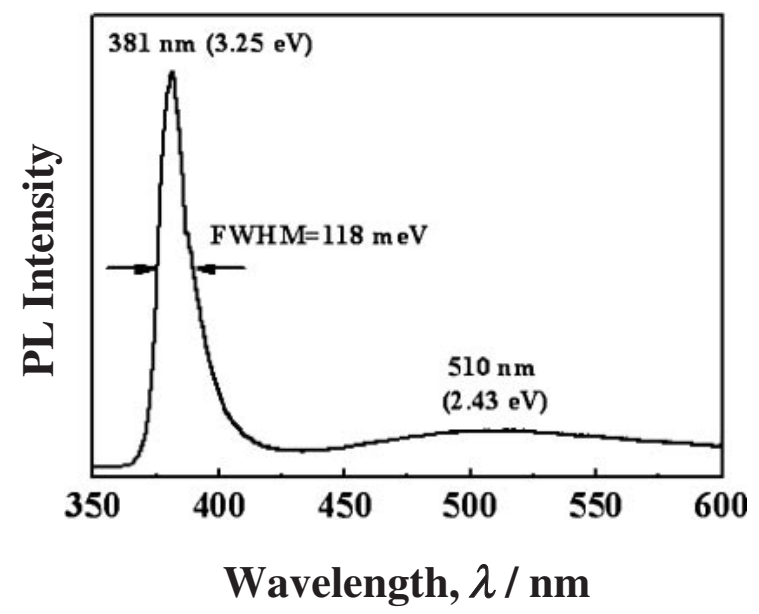

Fig. 5 PL spectrum of $\mathrm{ZnO}$ thin film at room temperature.

temperature) of sol-gel derived $\mathrm{ZnO}$ thin film. In the spectrum, the $\mathrm{ZnO}$ thin film contains a strong UV emission band at $381 \mathrm{~nm}(3.25 \mathrm{eV})$ and a very weak green emission band at $510 \mathrm{~nm}(2.43 \mathrm{eV})$, which can be attributed to the recombination of free excitons ${ }^{26)}$ and oxygen vacancies in the $\mathrm{ZnO}$ lattice. ${ }^{27,28)}$ In addition, the full-width half-maximum (FWHM) of the UV emission band was $118 \mathrm{meV}$. These results indicate that the crystallization of the $\mathrm{ZnO}$ thin film was just as good as $\mathrm{ZnO}$ epitaxial film produced by radio frequency (RF) or plasma-assisted MBE. ${ }^{28)}$

The $\mathrm{IrO}_{2} / \mathrm{ZnO} / \mathrm{IrO}_{2}$ MSM structure (a single-layer $\mathrm{IrO}_{2}$ electrode) with a circular spiral configuration was used to evaluate the UV detector performance.

The I-V characteristic of the $\mathrm{ZnO}$ photodetector was measured in darkness and under photoillumination in Fig. 6. Under a $5 \mathrm{~V}$ applied bias, it was found that the dark current was $4.32 \times 10^{-9} \mathrm{~A}$ and the photocurrent was $5.11 \times 10^{-7} \mathrm{~A}$. In other words, the photocurrent was about two orders of magnitude larger than the dark current. Similar results have

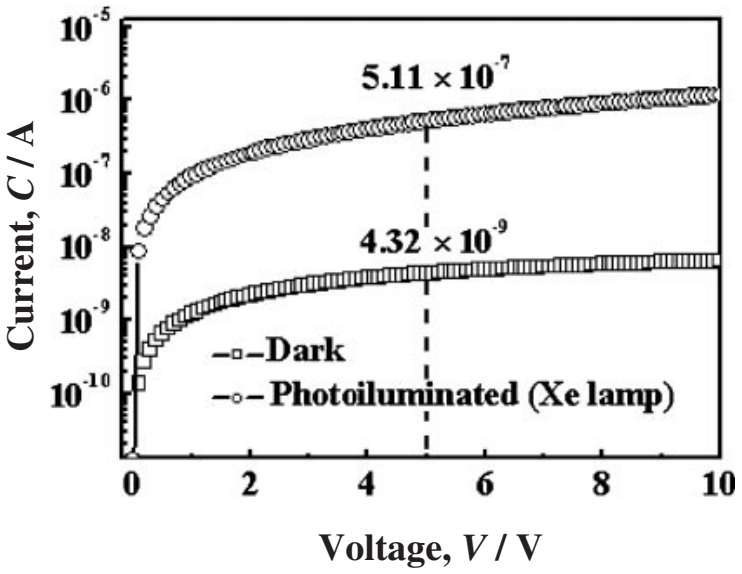

Fig. $6 \mathrm{I}-\mathrm{V}$ characteristics of $\mathrm{ZnO}$ photodetector measured in dark and under Xe illumination.

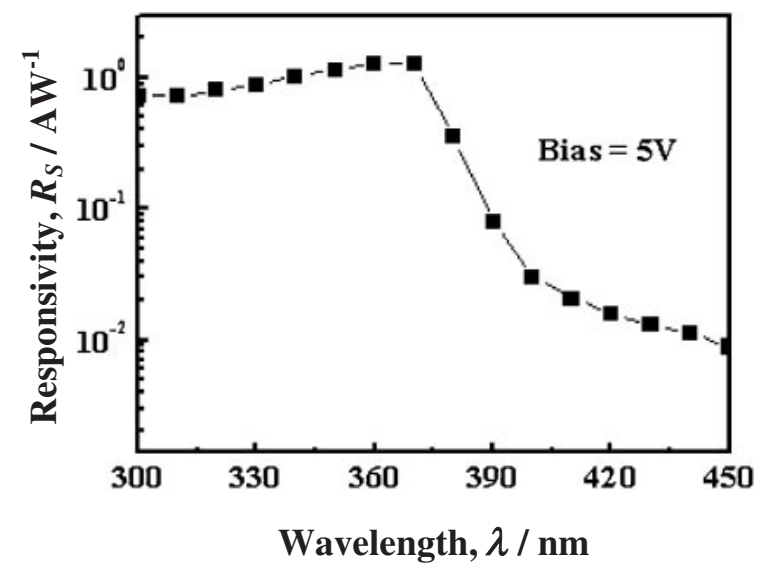

Fig. 7 The spectral response of the photocurrent measurement of $\mathrm{ZnO}$ MSM photodetector.

been obtained in relevant reports. ${ }^{12,29,30)}$ Notably, the photocurrent and dark current differed by less than one order of magnitude. It is clear that the electrical properties of the present thin film had been enhanced. In addition, Fig. 7 shows the spectral response of the photocurrent measurement on the MSM $\mathrm{ZnO}$ photodetector. For a light wavelength of $360 \mathrm{~nm}$ and $5 \mathrm{~V}$ applied bias, the response was $1.1 \mathrm{~A} / \mathrm{W}$ and the cut-off occurred at $370 \mathrm{~nm}$ (Fig. 7). Although the cut-off was not sharp, the present structure had higher photocurrent value than two orders of magnitude from 370 to $420 \mathrm{~nm}$.

The $600^{\circ} \mathrm{C}$ is lower that cannot help the growth of the nanopillars by sol-gel method. Notably, the $700^{\circ} \mathrm{C}$ film contained a very broad green emission which indicated that the electrons would be trapped by some defects (crystallized temperature is higher), resulted in the degeneration in the performance of photodetector. For reasons mentioned above, the $650^{\circ} \mathrm{C}$ film not only possessed nanopillars, but also had better crystallized structure that was more suitable for application in photodetector. In addition, it is noteworthy that the $\mathrm{IrO}_{2}$ electrode with the circular spiral configuration had the originality and better electrical properties. Furthermore, we can be confident that the sensitivity of the sol-gel derived $\mathrm{ZnO}$ thin film with nanopillars in the UV region is good enough for applications as UV photodetector materials. 


\section{Conclusion}

The $650^{\circ} \mathrm{C}$ sol-gel derived $\mathrm{ZnO}$ thin film not only possessed a better crystallized mechanism, but also had nanopillars on the film surface that were able to enhance the opto-electronic properties of the UV photodetector. For I-V measurement, the curve corresponded to the schottky metalsemiconductor contacts and the photo-generated current arrived at $5.11 \times 10^{-7}$ Ampere under a bias voltage of $5 \mathrm{~V}$. In addition, the photocurrent was 2 orders of magnitude larger than the dark current, quite adequate for a UV photodetector.

\section{Acknowledgements}

The authors are grateful to National Cheng Kung University, the Center for Micro/Nano Science and Technology (NCKU Project of D97-2700) and NSC 97-2221-E-006-018/ NSC 97-2622-E-006-009-CC3 for the financial support.

\section{REFERENCES}

1) P. Sandvik, K. Mi, F. Shahedipour, R. McClintock, A. Yasan, P. Kung and M. Razeghi: J. Cryst. Growth 231 (2001) 366-370.

2) C. Varenne, L. Maezt, J. Brunet, K. Wierzbowska, A. Pauly and B. Lauron: Thin Solid Films 516 (2008) 2237-2243.

3) M. H. Huang, Y. Wu, H. Feick, N. Tran, E. Weber and P. Yang: Adv. Mater. 13 (2001) 113-116.

4) T. Matsuda, M. Furuta, T. Hiramatsu, C. Li, H. Furuta and T. Hirao: Appl. Surf. Sci. 310 (2008) 31-35.

5) H. J. Lee, S. H. Lee, F. Yildiz and Y. H. Jeong: J. Mag. Mag. Mater. 310 (2007) 2089-2091.

6) X. Li, B. Zhang, H. Zhu, X. Dong, X. Xia, Y. Cui, K. Huang and G. Du: Appl. Surf. Sci. 254 (2008) 2081-2084.

7) P. K. Shin, Y. Aya, T. Ikegami and K. Ebihara: Thin Solid Films 516 (2008) 3767-3771.

8) M. Dutta, S. Mridha and D. Basak: Appl. Surf. Sci. 254 (2008) 2743 2747.

9) S. Hwangbo, Y. J. Lee and K. S. Hwang: Ceram. Int. 34 (2008) 1237-
1239.

10) D. Basak, G. Amin, B. Mallik, G. K. Paul and S. K. Sen: J. Cryst. Growth 256 (2003) 73-77.

11) P. T. Hsieh, Y. C. Chen, K. S. Kao and C. C. Cheng: J. Euro. Cera. Soc. 27 (2007) 3815-3818.

12) Z. Q. Xu, H. Deng, J. Xie, Y. Li and X. T. Zu: Appl. Surf. Sci. 253 (2006) 476-479.

13) S. J. Young, L. W. Ji, T. H. Fang, S. J. Chang, Y. K. Su and X. L. Du: Acta Mater. 55 (2007) 329-333.

14) S. N. Mohammad, Z. Fan, A. E. Botchkarev, W. Kim, O. Aktas and A. Salvador: Electron. Lett. 32 (1996) 598-599.

15) A. C. Schmitz, A. T. Ping, M. A. Khan, Q. Chen, J. W. Yang and I. Adesida: Electron. Lett. 32 (1996) 1832-1833.

16) S. J. Young, L. W. Ji, S. J. Chang, Y. P. Chen, K. T. Lam, S. H. Liang, X. L. Du, Q. K. Xue and Y. S. Sun: IET Optoelectron. 1 (2007) 135139.

17) L. F. Voss, L. Stafford, B. P. Gila, S. J. Pearton and F. Ren: Appl. Surf. Sci. 254 (2008) 4134-4138.

18) L. F. Mattheiss: Phys. Rev. B 13 (1976) 2433-2450.

19) H. W. Kim, S. H. Shim, J. H. Myung and C. Lee: Vacuum, in press (2008).

20) J. K. Kim, H. W. Jang, C. M. Jeon and J. L. Lee: Appl. Phys. Lett. 81 (2002) 4655-4657.

21) S. S. Thanawala, R. J. Baird, D. G. Georgiev and G. W. Auner: Appl. Surf. Sci. 254 (2008) 5164-5169.

22) K. J. Chen, T. H. Fang, F. Y. Hung, L. W. Ji, S. J. Chang, S. J. Young and Y. J. Hsiao: Appl. Surf. Sci. 254 (2008) 5791-5795.

23) S. B. Majumder, M. Jain, P. S. Dobal and R. S. Katiyar: Mater. Sci. Eng. B 103 (2003) 16-25.

24) Q. Yu, H. Yang, W. Fu, L. Chang, J. Xu, C. Yu, R. Wei, K. D Hongyang, M. Li and G. Zou: Thin Solid Films 515 (2007) 38403843.

25) P. T. Hsieh, Y. C. Chen, K. S. Kao, M. S. Lee and C. C. Cheng: J. Europ. Ceram. Soc. 27 (2007) 3815-3818.

26) W. D. Yu, X. M. Li and X. D. Gao: Appl. Phys. Lett. 84 (2004) 26852660.

27) Y. C. Liu, Y. W. Chen, C. L. Shao and S. X. Lu: J. Sol-Gel Sci. Techn. 39 (2006) 57-62.

28) S. J. Young, L. W. Ji, S. J. Chang and Y. K. Su: J. Cryst. Growth 29 (2006) 43-47.

29) J. H. He, Y. H. Lin, M. E. McConney, V. V. Tsukruk, Z. L. Wang and G. Bao: J. Appl. Phys. 102 (2007) 084303.

30) Z. Q. Xu, H. Deng, J. Xie, Y. Li, Y. Li, X. Zu and S. Xue: J. Sol-Gel Sci. Techn. 36 (2005) 223-226. 